\title{
ФРАМБОИДАЛЬНЫЙ ПИРИТ В СЛЕДАХ ЖИЗНЕДЕЯТЕЛЬНОСТИ ОРГАНИЗМОВ В ОСАДКАХ НИЖНЕГО КЕМБРИЯ ЭСТОНИИ
}

Фрамбоиды пирита были обнаружены в ходе электронно-микроскопического изучения ходов мягкотелых бентосных организмов в глинистых осадках кембрия. Эти ходы, покрытые тонкозернистыми пиритовыми образованиями, имеют вид тонких лент шириной от 1 до 10 мм (табл. I, $1,2)$. На свежем изломе окраска их обычно светло-коричневая или бежевая со слабым серебристым блеском, при длительном хранении - темно-коричневая или даже черная. Первоначально эти ходы представляли собой, видимо, цилиндрические или овальные горизонтальные каналы, которые после уплотнения глины под воздействием одностороннего давления превратились в плоские, почти безразмерные в вертикальном направлении ленты. Слизистые выделения илороющих в этих каналах, а порой и сами трупы организмов создали благоприятную питательную среду для интенсивной жизнедеятельности бактерий, в частности сульфатредукторов. В результате этого поры и заполнялись тонкозернистыми агрегатами пирита различных форм, среди которых найдена и не очень распространенная - фрамбоидальная. Поскольку минерализация органических выделений в этом случае происходила явно в раннем диагенезе, а вследствие прогрессирующего уплотнения вмещающих глин эти очаги быстро трансформировались в закрытые системы, данная находка весьма сужает условия формирования рассматриваемого типа пирита и может внести дополнительную информацию в дискутируемые положения о генезисе таких образований.

Понятие «фрамбоидальный пирит» было впервые использовано T. Растом (Rust, 1935) для обозначения сферического минерального агрегата, сложенного из мелких кристалликов пирита. Агрегат напоминает ягоды малины (фр. framboise). Позднее это название прочно вошло в литературу и применяется сейчас для обозначения однозначно понимаемых образований. В большинстве случаев фрамбоиды имеют диаметр в пределах 4-25 мкм, слагающие их кристаллики - 0,20,7 мкм. Несмотря на такое однообразие морфологии, генезис этих образований до сих пор трактуется по-разному.

Фрамбоиды, найденные в ходах илороющих организмов раннего кембрия, заполняют исследуемый объект не сплошной массой, а вместе с рассеянными кристаллами, по размеру соизмеримыми с содержащимися в фрамбоидах. Поровое пространство между ними свидетельствует о существенном сокращении объема твердой фазы при образовании фрамбоидов и кристаллического пирита. Все же фрамбоидальный пирит составляет около $50 \%$ от общей массы пирита в этих органогенных каналах (табл. I, 3; табл. II, 1). Создается впечатление, что они больше концентрируются к средним, наиболее утолщенным участкам пиритизированных лент. Следовательно, их формирование могло быть стимулировано свободным пространством в центре ходов жизнедеятельности организмов. 


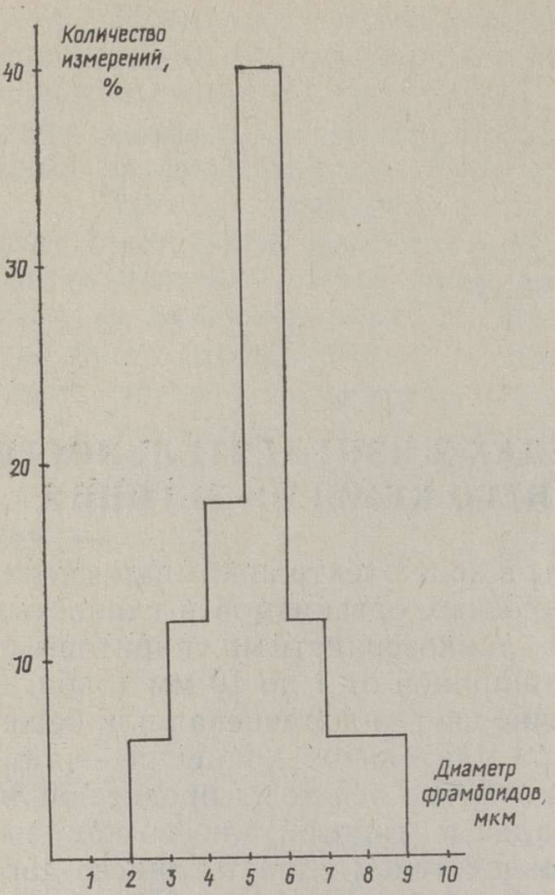

Распределение фрамбоидов по диаметру. Количество измерений 150 .

Характер фрамбондального пирита в рассматриваемом объекте несколько своеобразен. Во-первых, отмечается несущественная вариация размеров фрамбоидов - преимущественно в пределах $3-7$ мкм (рисунок). Фрамбоидов диаметром меньше 2 мкм и больше 9 мкм в исследованных препаратах не обнаружено. Выдерживаются и размеры индивидуальных кристалликов обычно 0,4-1 мкм (табл. I, 4; табл. II, 2). В литературе указаны более широкие пределы - соответственно 2-50 мкм и 0,2-5 мкм (Kalliokoski, Cathles, 1969; Love, 1971; Antun, 1973; Cridle, 1974; и др.). Следовательно, фрамбоиды данного объекта явно тяготеют к наиболее мелким представителям этой группы образований. Во-вторых, обращают на себя внимание разнообразная морфология слагающих кристаллов и отсутствие какой-либо ориентировки в их расположении. Среди кристаллографических форм можно видеть октаэдры (111), пентагон-додекаэдры (210), в меньшем количестве кубы (100) или его комбинации с другими формами. Упаковка кристалликов в фрамбоиде в нашем случае не очень плотная - ее можно оценивать как дисперсионную или переходную по классификации Кизильштейна и Минаевой (1983).

Третья важная особенность фрамбоидального пирита - его кристаллическая структура, выражающаяся в параметре решетки $(a)$. В изученных образцах пирита, содержащих не менее $40 \%$ фрамбоидальной формы, параметр решетки, по определениям Т. Калласте, занижен на $0,002 \AA(a=5,4152-5,4156 \AA)$ как относительно нормальных значений для других пиритов венда и кембрия Эстонии $(a=5,4173 \AA)$, так и относительно данных из других обобщений ( $a=5,4175 \AA$; Vaughan, Craig, 1975). В то же время в литературе есть указания на более высокие значения параметра решетки у фрамбоидального пирита $-5,4201 \AA$ (Сералин и др., 1981). Причины таких расхождений сейчас не ясны, по-видимому, данные вариации отражают различные условия формирования рассматриваемого типа пирита.

По генезису фрамбоидального пирита высказываются очень различные мнения - начиная с его формирования при повышенных температурах и кончая предположением о псевдоморфозе этих агрегатов по колониям бактерий. Все же более приемлемой следует считать концепцию об определяющей роли биогенных коллоидных физнко-химических процессов при формировании этих агрегатов (Kribek, 1977; Love, 1967; Леин и др., 1978). Она объясняет сферическую форму их, а также условия появления соизмеримых мелких кристаллов с пустотами и аморфным цементом между ними (раскристаллизация коллоидного геля). Естественно, что такие процессы чаще развиваются в тонкодисперсном осадке, поэтому и фрамбонды пирита обычно устанавливаются в глинах. Рассматриваемая находка в лонтоваской свите вполне согласуется с этими представлениями. В качестве дополнительных благоприятствующих факторов здесь имели место и созданная биотурбацией структурная 

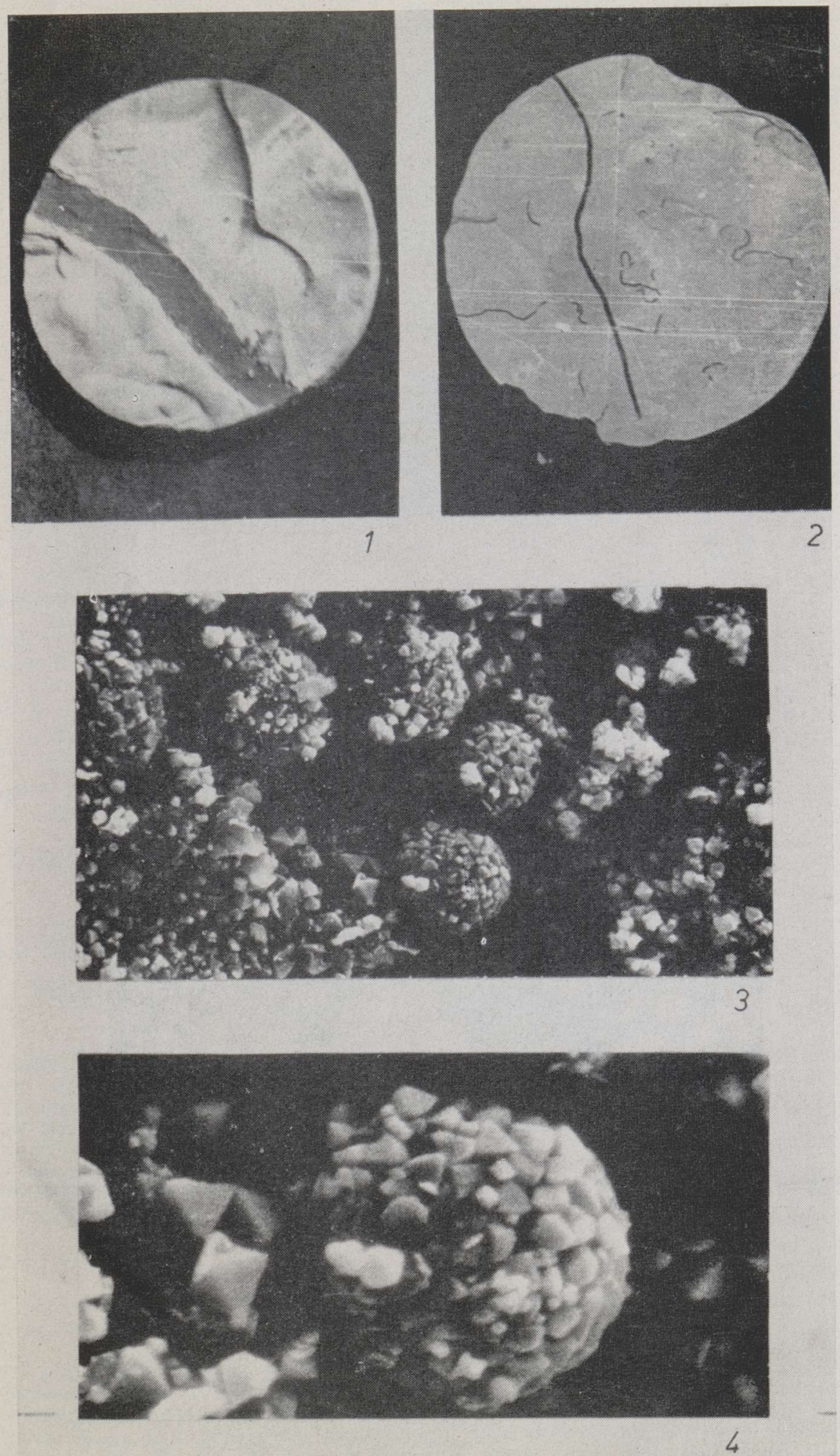

1, 2. Пиритовые ленты разных размеров - следы жизнедеятельности мягкотелых бентосных организмов в глинах лонтоваской свиты кембрия. Уменыш. $0,8 \times$.

3. Скопление фрамбоидов в материале заполнения следов жизнедеятельности организмов: видно наличие свободного пространства между фрамбоидами. Увел. $2500 \times$. 4. Упаковка кристаллов во фрамбоиде. Увел. $7500 \times$. 

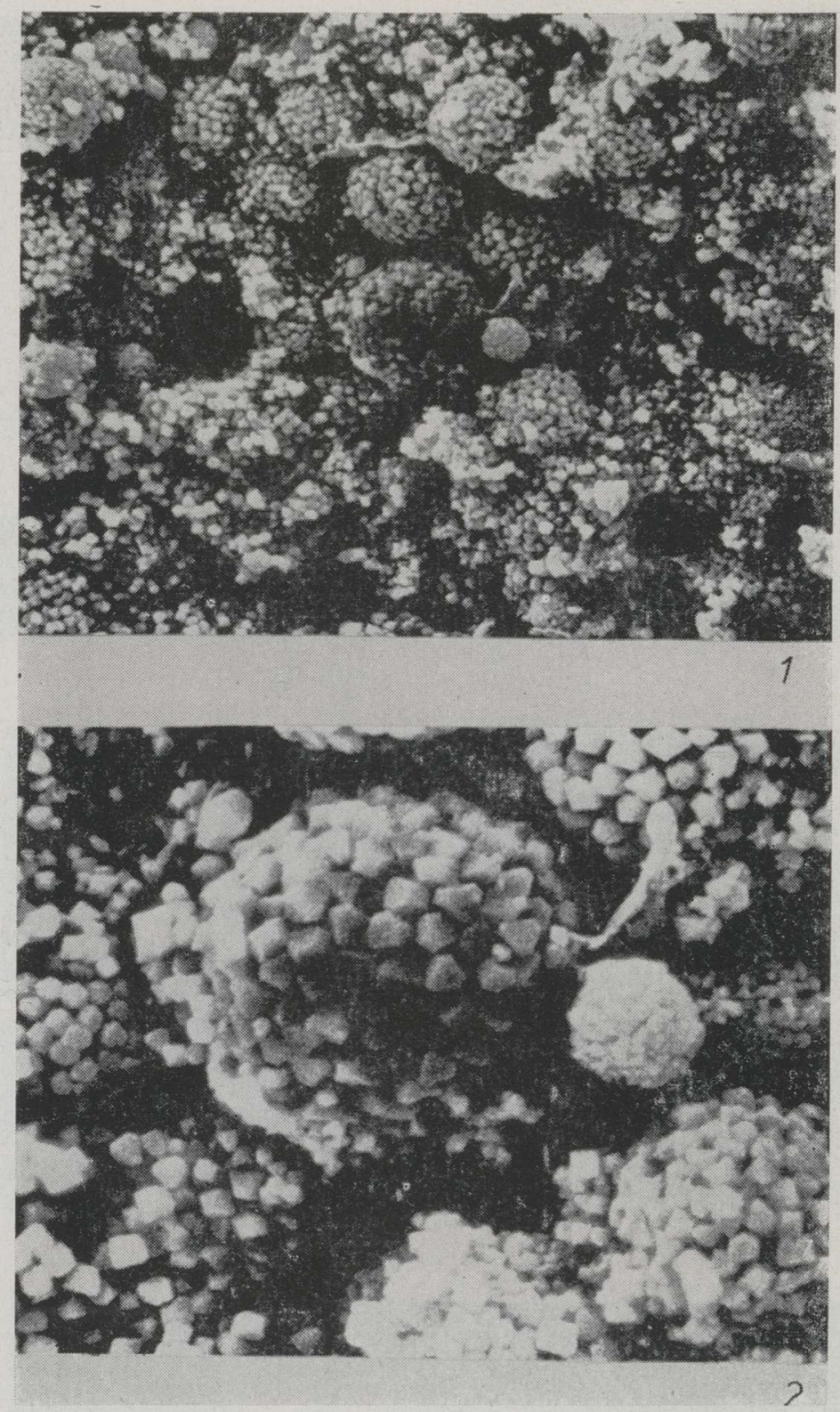

1. Богатое скопление фрамбоидов: виден переход в часть пиритизнрованной ленты без фрамбоидальной структуры. Увел. 17Е0х.

2. Фрамбоиды пирита с различной упаковкой кристаллов. Увел. $5000 \times$. 
гетерогенность высокопластичного глинистого осадка, и неравномерно распределяющееся органическое вещество - очаги интенсивной деятельности бактерий-сульфатредукторов. В какой мере в этом процессе участвовали метастабильные фазы моносульфида железа (FeS), по нашему материалу сейчас сказать трудно. Однако как объект дальнейшего изучения этих явлений пиритизированные ходы илоедов лонтоваской свиты, несомненно, заслуживают серьезного внимания.

\section{Л ИТЕ РА Т У Р А}

Кизильитейн Л. Я., Минаева Л. Г. Фрамбоидальные формы пирита: строение, условия образования, использование для геохимической диагностики фаций // Изв. Сев.Кавказ. науч. центра высш. школ. Естеств. н., 1983, № 1, 77-81.

Леин А. Ю., Сидоренко Г. А., Волков Н. Н., Шевченко А. Я. Диагенетические макинавит, мельниковит (грейгит) и пирит в осадках на профиле через Тихий океан и в осадках Калифорнийского залива // Докл. АН СССР, 1978, 238, № 3, 698700.

Сералин Р. С., Слюсарев А. П., Пронин А. П., Лискин В. Г. Некоторые структурнотипоморфные признаки пирита и их генетическое значение // Изв. АН КазССР. Сер. геол., 1981, № 4, 13-20.

Antun, P. Sur la structure globulitique d'une pyrite sédimentaire du Cambrien de Rochelinval (Massif de Stavelot) // Ann. Soc. Geol. Belg., 1973, 96, 403-410.

Criddle, A. J. A preliminary description of microcrystalline pyrite from the nannoplankton ooze at Site 251, southwest Indian Ocean // Init. Repts. Deep Sea Drill. Proj., 26. Washington, 1974, 603-611.

Kalliokoski, J., Cathles, L. Morphology, mode of formation and diagenetic changes in framboids // Bull. Geol. Soc. Finland, 1969, 41, 125-133.

Kribek, B. Origin of framboidal pyrite // Cas. miner. a geol., 1977, 22, N 1, 11-18.

Love, L. G. Early diagenetic iron sulphide in recent sediments of the Wash (England) // Sedimentology, 1967, 9, 327-352.

Love, L. G., Curtis, C. D.!' Brockley, H. Framboidal pyrite; morphology revealed by electron microscopy of external surfaces // Fortschr. mineral., 1971, 48, 259-264.

Rust, C. W. Colloidal primary copper ores at Cornwall Miner, Southeastern Missouri // J. Geology (Chicago), 1935, 43, 398-426.

Vaughan, O. J., Craig, J. R. Mineral chemistry of metal sulfides. Cambridge University Press, 1975.

Тартуский университет

Поступила в редакцию 10/IX 1989

\section{Indrek TAMMEAID}

\section{FRAMBOIDNE PURIIT EESTI ALAMKAMBRIUMI BIOTURBATSIOONI JÄLGEDES}

Lontova kihistu savides laialdaselt levinud lamedate roomamisjälgede püriidistunud täidete uurimisel skaneeriva elektronmikroskoobiga leiti neis hulgaliselt framboidset püriidivormi. Framboididele on iseloomulik mõõtmete vähene varieeruvus ja neid moodustavate kristallide morfoloogia märkimisväärne mitmekesisus ilma kristallide täheldatava eelisorienteerituseta. Struktuurselt on framboidsele püriidile omane vōreparameetri tunduv vähenemine võrreldes normaalse püriidistruktuuriga.

Tekkelt on vaadeldav püriit ilmselt varadiageneetiline, kujunenud organismide poolt käikudesse jäetud eritiste mineraliseerumisel.

\section{Indrek TAMMEAID}

\section{FRAMBOIDAL PYRITE FROM ESTONIAN LOWER CAMBRIAN TRACE FOSSILS}

Pyritized biogenic trace fossils (Table I, 1, 2) are very common in the Lontova argillaceous deposits of Estonia. The examination of their flat forms under a scanning electromicroscope established the existence of framboidal pyrite (Table I, 3, 4). The sizes of framboids are of a rather small variety (Fig.), while their crystals are morphologically considerably variable. The structure of framboidal pyrite differs from the normal pyrite structure having noticeably smaller reticulation.

Framboidal pyrite was probably formed during early diagenetic processes by the mineralization of mucous films of organisms. 